\title{
Article \\ Numerical Analysis of Filament Wound Cylindrical Composite Pressure Vessels Accounting for Variable Dome Contour
}

\author{
Kumar C. Jois *(D), Marcus Welsh (D), Thomas Gries and Johannes Sackmann \\ Institut für Textiltechnik Aachen (ITA), RWTH Aachen University, 52074 Aachen, Germany; \\ marcus.welsh@rwth-aachen.de (M.W.); Thomas.Gries@ita.rwth-aachen.de (T.G.); \\ Johannes.Sackmann@ita.rwth-aachen.de (J.S.) \\ * Correspondence: kumar.jois@rwth-aachen.de
}

check for

updates

Citation: Jois, K.C.; Welsh, M.;

Gries, T.; Sackmann, J. Numerical

Analysis of Filament Wound

Cylindrical Composite Pressure

Vessels Accounting for Variable Dome

Contour. J. Compos. Sci. 2021, 5, 56.

https://doi.org/10.3390/jcs5020056

Academic Editor: Frédéric Jacquemin

Received: 15 January 2021

Accepted: 8 February 2021

Published: 11 February 2021

Publisher's Note: MDPI stays neutral with regard to jurisdictional clai$\mathrm{ms}$ in published maps and institutional affiliations.

Copyright: $\odot 2021$ by the authors. Licensee MDPI, Basel, Switzerland. This article is an open access article distributed under the terms and conditions of the Creative Commons Attribution (CC BY) license (https:// creativecommons.org/licenses/by/ $4.0 /)$.

\begin{abstract}
In this work, the stress distribution along cylindrical composite pressure vessels with different dome geometries is investigated. The dome contours are generated through an integral method based on shell stresses. Here, the influence of each dome contour on the stress distribution at the interface of the dome-cylinder is evaluated. At first, the integral formulation for dome curve generation is presented and solved for the different dome contours. An analytical approach for the calculation of the secondary stresses in a cylindrical pressure vessel is introduced. For the analysis, three different cases were investigated: (i) a polymer liner; (ii) a single layer of carbon-epoxy composite wrapped on a polymer liner; and (iii) multilayer carbon-epoxy pressure vessel. Accounting for nonlinear geometry is seen to have an effect on the stress distribution on the pressure vessel, also on the isotropic liner. Significant secondary stresses were observed at the dome-cylinder interface and they reach a maximum at a specific distance from the interface. A discussion on the trend in these stresses is presented. The numerical results are compared with the experimental results of the multilayer pressure vessel. It is observed that the secondary stresses present in the vicinity of the dome-cylinder interface has a significant effect on the failure mechanism, especially for thick walled cylindrical composite pressure vessel. It is critical that these secondary stresses are directly accounted for in the initial design phase.
\end{abstract}

Keywords: composite pressure vessel; CPV; COPV; stress distribution; secondary stress; carbonepoxy composites; cylindrical pressure vessel; failure mechanism; numerical analysis

\section{Introduction}

Pressure vessels are containers used to store fluid under pressure. They are more commonly used to store gases, rather than liquids, due to the compressibility and hence the possibility to achieve high energy density [1]. In stationary applications, where weight and space are not of much concern, pressure vessels are usually manufactured using metals. However, the situation becomes rather interesting for mobile applications, like propellant tanks for rockets or satellites, compressed natural gas and hydrogen tanks for automotive application, etc. While the shape of the pressure vessel can vary depending on the application, cylindrical pressure vessels are the most common among them. In this study, cylindrical pressure vessels and some of their design aspects are addressed.

There are two types of stresses, namely hoop and longitudinal stress, acting on a cylinder under internal pressure. An isotropic material for manufacturing these cylinder leads to a redundant material usage. This has a considerable impact at higher pressure, especially for mobile applications. Composite materials, due to the possibility of obtaining highly orthotropic structures, offer an alternative to purely isotropic materials. A vessel manufactured using composite materials is referred to in this article as a composite pressure vessel (CPV). More specifically, CPV's are often used when one requires high-strength, minimal weight, or both simultaneously. This happens to be the case, for example, with solid rocket motors, which generally have quite high internal pressure to achieve high thrust; 
however, they must also be light-weight in order to maximize the available payload mass that can be delivered into orbit [2].

CPV's, as a technology, are quite old and were mostly used in the early days for rocket motor casings and space related applications [2]. While this technology may be perfected for space applications, where manufacturing speeds and costs do not play a major role, automotive applications, however, have costs limits and require high manufacturing speeds. Over the past decade there has been a major movement towards alternatives to the conventional combustion engine due to its "enhancing" of the greenhouse effect. One proposed alternative is the hydrogen fuel cell automobile, which would require a hydrogen source. Due to some practical reasons, gaseous hydrogen has found its way to the market for this purpose, compared to cryogenic hydrogen. Hydrogen, having a density of $0.0838 \mathrm{~kg} / \mathrm{m}^{3}$ (energy density of $10 \mathrm{MJ} / \mathrm{m}^{3}$ ) at $273 \mathrm{~K}$ and $0.1 \mathrm{MPa}$, must be stored at higher pressure to achieve the required coverage distance. For automotive application, the pressure is about $70 \mathrm{MPa}$, at which hydrogen has a density of $41.74 \mathrm{~kg} / \mathrm{m}^{3}$ at $273 \mathrm{~K}$ (energy density of $5000 \mathrm{MJ} / \mathrm{m}^{3}$ ) [1].

There are different types of CPV based on the composite coverage. Here, a Type IV pressure vessel is considered. This consists of a polymer liner and a composite overwrap, manufactured by means of filament winding. Other techniques like overbraiding is also known to be used for cylindrical pressure vessel [3]. The concept of the filament winding is rather simple: a long, continuous fibre is wrapped around a form, referred to as a mandrel or liner, until the final form and thickness is achieved. The matrix material, most commonly an epoxy, can be applied in a few different ways: the fibres can be impregnated with the epoxy before winding begins (Prepregs) or after winding has been completed (through suitable resin infusion process), or the fibres can be impregnated with the epoxy during the winding process, in which the fibres are pulled through a bath containing the epoxy [4]. The resins can be either thermosets (e.g., epoxy-based, vinyl ester) or thermoplastics (usually in Prepreg form).

Keeping lightweight and cost in mind, a minimum amount of fibre must be used. In filament winding, though a continuous process, one can differentiate the composite overwrap into different layers or plies. There are different plies oriented at different angles (in this case, the vessel longitudinal axis is considered as $0^{\circ}$ ). Due to a physical network of fibres, netting theory is commonly used for a preliminary analysis [5,6]. Zhang et al. [7] uses netting theory to determine the laminate layout for the cylindrical section. Classical lamination theory is also among the techniques [8]. Another technique for analysis is finite element tools/solvers (FE). Gray and Moser [9] discusses the effect of material and geometric nonlinearity on designing of CPV's, by considering an axisymmetric model. Multhoff and Krieger [10] present an effective design procedure for hydrogen storing CPV. A software tool is developed for a rapid modelling and analysis of CPV. Magneville et al. [11] discusses the various modelling parameters for Type IV composite pressure vessels for hydrogen storage. Various FE techniques are provided for the analysis of CPV [12-14].

The load sharing ability of different liner material is compared in [15], where the stresses along the length of the liner is plotted. To this end, they mention about the complex stress state at the dome-cylinder interface, where stress peaks are observed, irrespective of the liner material. Lin et al. [16] observed higher matrix cracking at the dome-cylinder interface through the SEM analysis, in comparison to the cylindrical section. This region was seen to be prone to high stress concentration during the hydrostatic test. This article analyses the effect of different dome geometries on the stress distribution at the domecylinder interface.

\section{Dome Design}

A cylindrical pressure vessel can be divided into three sections; a cylindrical section and two domes. The valves or boss is attached to one end of the dome as shown in the Figure 1 and these are usually symmetric, meaning both domes are similar, but they can also vary depending on the application. 


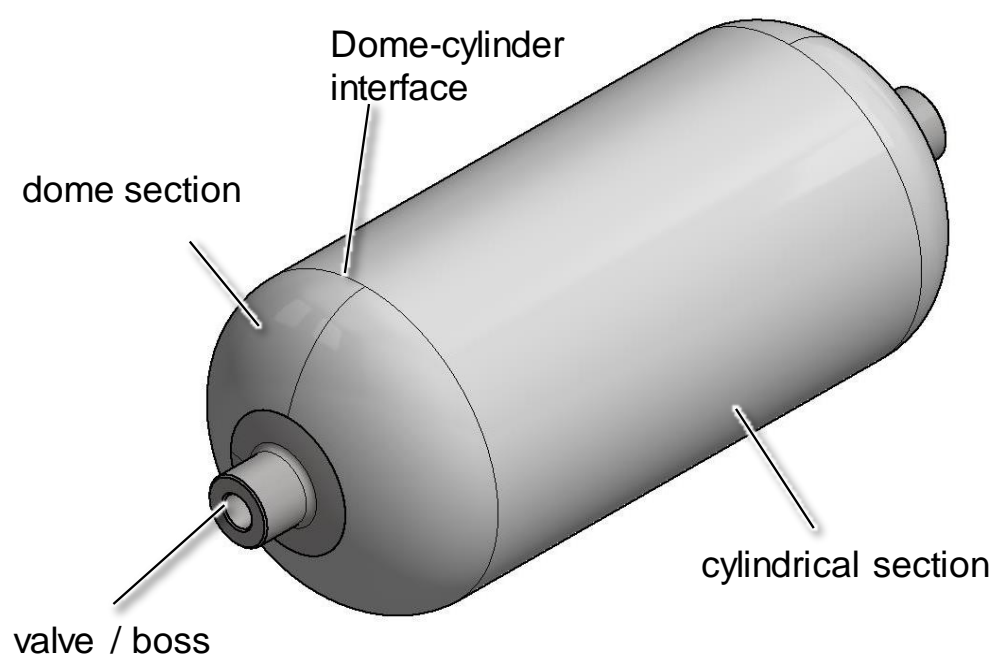

Figure 1. Sections of a polymer liner/mandrel with boss connection.

In filament winding, one can differentiate between geodesic and non-geodesic paths for the fibre. While the designing and the winding of the cylindrical section can be done with relative ease, doing this for the dome section can be quite challenging. Since orthotropic materials are used to make CPV's, one begs the question as to whether there is an optimal dome contour that can be achieved. In an ideal situation (minimum weight and maximum capacity), all the fibres are equally stressed in the deformed shape; a state known as Isotensoid. Netting theory is commonly used to determine this shape. In Filament Winding: A Unified Approach [17], a dome generation technique is derived in great detail. Since the focus of this article is on the effect of these dome contours from the numerical analysis point of view, only the most important concept and formulation is presented in the next section.

\subsection{Geodesic Paths}

Geodesic winding refers to a winding method by which a fibre follows the shortest path connecting two points on a surface. This path is unique, meaning that for a given dome geometry, only one geodesic path exists, which is defined by the Clairaut equation [2,17]:

$$
\alpha=\arcsin \left(\frac{1}{Y}\right)=\arcsin \left(\frac{c}{\rho}\right)
$$

where $\alpha$ is the winding angle, $c$ is the polar opening radius, and $\rho$ is the radial coordinate on the dome. When one chooses the radial coordinate to be equal to the cylinder radius, then the required winding angle at the dome equator is determined. By changing the polar opening radius or dome equator radius, different geodesic winding angles can be determined.

Geodesic paths have the unique property of requiring no friction in order to stay on the path, which will be expanded upon in the section pertaining to nongeodesic winding. Although it is impossible to have zero friction between surfaces, this convenient property allows one to forgo any friction calculations when determining a winding pattern.

\subsection{Non-Geodesic Paths}

Non-geodesic winding refers to a method by which a fibre follows any path, excluding the shortest, between two points on a surface. Unlike a geodesic path, there are many non-geodesic paths that can cover a given surface. $\mathrm{Zu}$ et al. [18] presents a novel approach for the design and analysis of filament wound vessels based on non-geodesic winding pattern. Since there are many possible non-geodesic paths, one is not restricted by the required winding angle determined in Equation (1); however, one must now determine the required friction between the surface and the fibre in order to stay on the path. Koussios 
and Bergsma [19] provide a method to determine friction. Although a relationship between the friction and surface curvatures will be briefly discussed, a detailed derivation can be found in [17].

Consider an elementary piece of a surface of revolution, as in Figure 2:

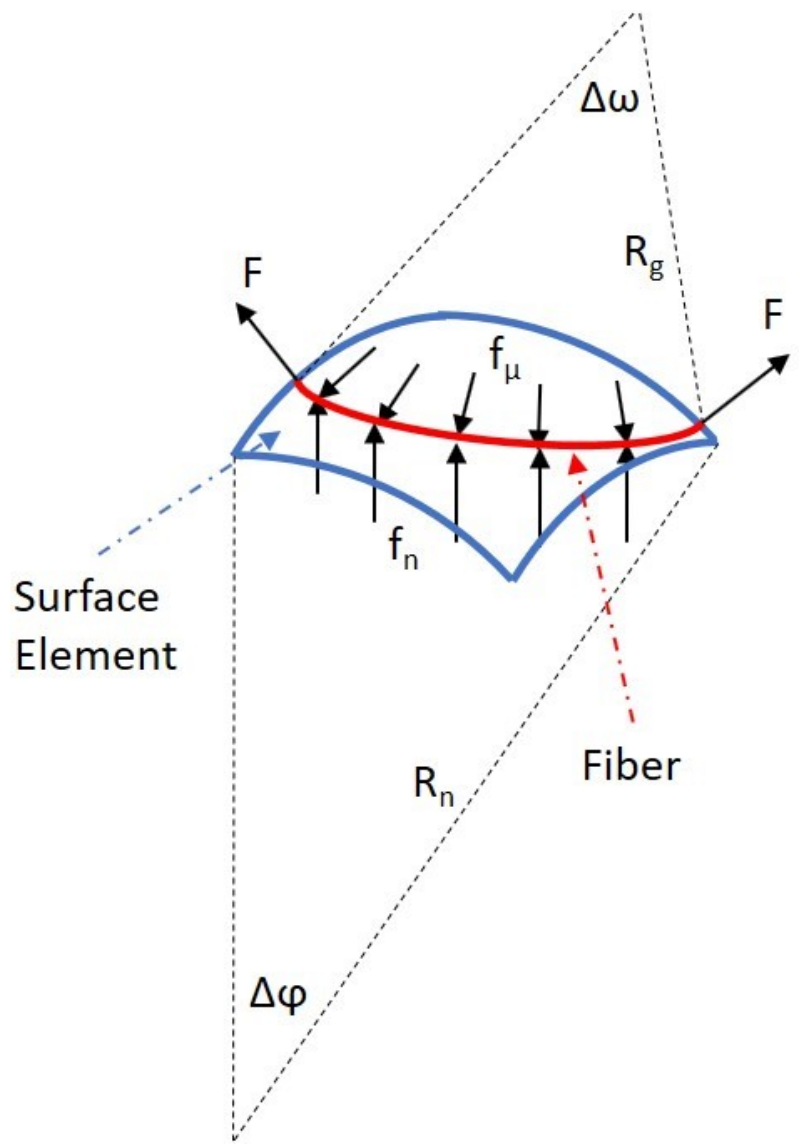

Figure 2. Forces acting on the fibre on an arbitrary curvature.

Here, $R_{n}$ is the radius of normal curvature, $R_{g}$ is the radius of geodesic curvature, $F$ is the tension in the fibre, $f_{n}$ is the normal force per unit length, and $f_{\mu}$ is the lateral force per unit length. If the fibre is to stay on a given path, the following equations of equilibrium must be satisfied:

$$
\begin{aligned}
& f_{n} R_{n} \Delta \psi=2 F \sin \frac{\Delta \psi}{2} \approx F \Delta \psi \Longrightarrow f_{n}=\frac{F}{R_{n}} \\
& f_{\mu} R_{g} \Delta \omega=2 F \sin \frac{\Delta \omega}{2} \approx F \Delta \omega \Longrightarrow f_{\mu}=\frac{F}{R_{g}}
\end{aligned}
$$

where the Equation (2) describes the equilibrium of forces normal to the surface and the Equation (3) shows the equilibrium of forces laterally on the surface. The path stability condition is then:

$$
\mu \geqslant \frac{\left|\frac{F}{R_{n}}\right|}{\left|\frac{F}{R_{g}}\right|}=\frac{\left|R_{n}\right|}{\left|R_{g}\right|}=\frac{\left|k_{g}\right|}{\left|k_{n}\right|}
$$

where $k_{g}$ and $k_{n}$ are the geodesic and normal curvatures, respectively, and $\mu$ is the coefficient of static friction. In the case of a geodesic path, the geodesic curvature becomes zero, which validates the statement in the previous section that fibres on geodesic paths do not require friction to remain on their paths [17]. 


\subsection{Dome Profile Equation}

The generation of the pressure vessel, and more specifically the dome contour, followed the design process outlined in $[2,17]$. This approach for generating the dome profiles were chosen, due to the ease with which one can vary the parameters and thus generate different contours. Additionally, using this approach does not limit us to the single dome profile generated using netting theory but includes this profile amongst various others. Here, the meridian profiles are generated by numerical integration of the following equation:

$$
Z^{\prime}(Y)=\frac{Y\left(Y^{2}+r Y_{e q}^{2}\right)}{\sqrt{\left(\frac{K+Y^{2}-1}{K+Y_{e q}^{2}-1}\right)^{(K+1)}(1+r)^{2} Y_{e q}^{6}-Y^{2}\left(Y^{2}+r Y_{e q}^{2}\right)^{2}}}
$$

where

$$
\begin{gathered}
Y=\frac{\rho}{c} \\
Y_{e q}=\frac{R}{c} \\
Z=\frac{z}{c} \\
K=\frac{E_{2}\left(1+v_{12}\right)}{E_{1}\left(1+v_{21}\right)} \\
r=\frac{F}{\pi R^{2} P_{\text {in }}}
\end{gathered}
$$

Here, $Y$ is the dimensionless radius, $\rho$ is the radial coordinate, $c$ is the polar boss opening radius, $Y_{e q}$ is the dimensionless radius at the cylinder wall, $Z$ is the dimensionless height of the dome, and $z$ is the height coordinate of the dome. Additionally, the dimensionless parameter $K$ is referred to as the degree of material orthotropy and is defined by the material properties of the laminate layer: $E_{2}$ is Young's modulus perpendicular to the fibre direction, $E_{1}$ is Young's modulus parallel to the fibre direction, $v_{12}$ is the Poisson's ratio in the fibre direction with respect to tension perpendicular to the fibre, and $v_{21}$ is defined exactly opposite to $v_{12}$. Lastly, the dimensionless force parameter $r$ is the ratio of the external axial forces divided by the internal pressure. The bounds of integration is between $Y_{\min }$ and $Y_{e q}$.

In order to obtain this equation, a few key assumptions were made: the wall thickness is considered to be "small", therefore bending effects are negligible. Additionally, the fibres intersect at the meridian with winding angles of both $[+\alpha,-\alpha]$, thus preventing in-plane shear. An important result from this derivation is that the shell stress ratio is a function of the meridian shape [2].

As a control measure, the profiles generated by our fourth-order Runge-Kutta integration script, plotted in Figure 3. The dome profiles generated by our script were in agreement and converged with increasing integration step count.

Since the Clariaut equation is only dependent upon the radial coordinate and the polar opening radius, the winding angles on the dome should be identical for pressures vessels having different dome contours but the same value of $Y_{e q}$. Again, the use of this equation implies that a pressure vessel is covered by geodesic fibre paths. 


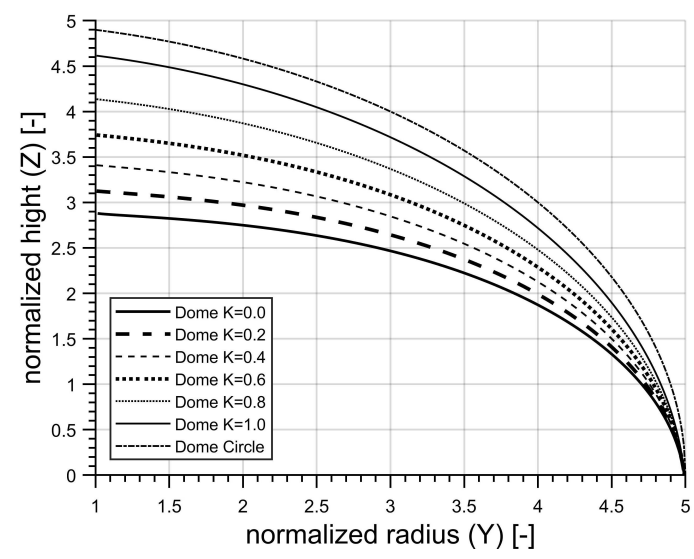

Figure 3. Dome contours generated by our fourth-order Runge-Kutta script.

Using Equation (1) introduced above, the winding angle is easily obtained from $Y(\rho)$ at each integration step and is plotted for each contour in Figure 4 . These winding angles correspond to a $Y_{e q}=4.6$ used in the simulations that follow in the next section.

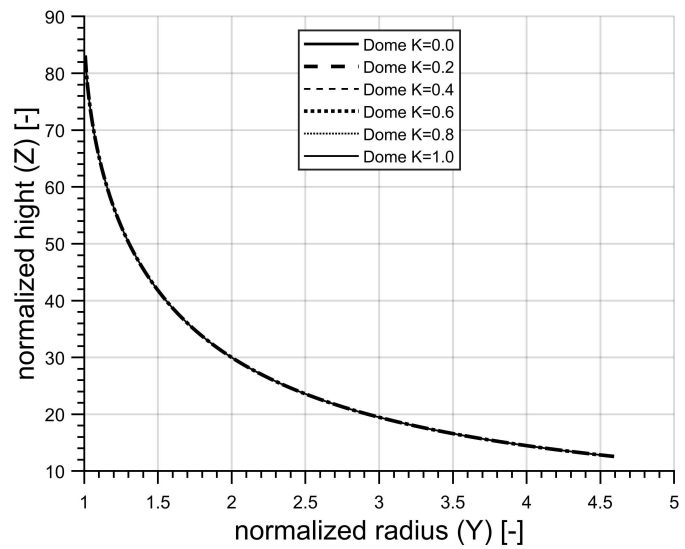

Figure 4. Winding angles for each contour.

\section{Dome-Cylinder Interface}

While the stresses in the dome and cylinder, referred to as primary stresses, can be calculated with relative ease, it becomes interesting and rather slightly complicated at the interface between the dome and cylinder. These stresses are termed here as secondary stresses [20,21]. While in-plane tension and compression constitute primary stresses, secondary stresses include out of plane stresses, namely bending and shear. Such separation of stresses can be made in any arbitrary shell of revolution. Usually primary stresses dominate the secondary stresses. Due to the very small magnitude of secondary stresses, they are mostly neglected in many calculations. The influence of these stresses in a CPV is discussed in detail in the result section.

In a shell of revolution, principle stresses act in the meridional and tangential directions. In simple terms, meridians run from pole to pole and tangents in the perpendicular direction. For a shell under internal pressure, the equilibrium equation is given by:

$$
\frac{\sigma_{m}}{R_{m}}+\frac{\sigma_{t}}{R_{t}}=\frac{p}{t}
$$

where $p$ and $t$ are the local internal pressure and thickness of the shell. $R_{m}$ and $R_{t}$ are the radii of curvature in the meridional and tangential direction of the element under consideration, respectively. 
For a cylindrical pressure vessel (with a cylinder radius of $r_{0}$, the two primary stresses can be calculated separately for a cylinder Equation (7) and for a dome Equation (8).

$$
\begin{gathered}
\frac{\sigma_{m}}{\infty}+\frac{\sigma_{t}}{R_{t}}=\frac{p}{t} \\
\sigma_{t}=\frac{p r_{0}}{t}, \sigma_{m}=\frac{p r_{0}}{2 t} \\
R_{m}=R_{t}=r_{0} \\
\frac{\sigma_{m}}{r_{0}}+\frac{\sigma_{t}}{r_{0}}=\frac{p}{t} \\
\sigma_{t}=\sigma_{m}=\frac{p r_{0}}{2 t}
\end{gathered}
$$

while the meridional stresses, often referred to as longitudinal stresses, in both the cylinder and the hemisphere are the same, the tangential stress, also called hoop stresses, in the cylinder is twice that in the dome. To visualise the consequence of this, strain in both cylinder and dome are calculated using Hooke's law, Equation (9).

$$
\begin{aligned}
\epsilon_{m} & =\frac{1}{E}\left[\sigma_{m}-v \sigma_{t}\right] \\
\epsilon_{t} & =\frac{1}{E}\left[\sigma_{t}-v \sigma_{m}\right]
\end{aligned}
$$

Since both the segments are physically connected, the dome will try to pull the cylinder inwards while the cylinder will try to pull the dome outwards. If both the parts are disjointed, then the difference in the radii can be calculated as (see [21]):

$$
\delta=\frac{p r^{2}}{2 h E}
$$

These two parts are held together by equal but opposite transverse shear forces and bending moments, both of which act on the faces at the dome-cylinder interface, as shown in the Figure 5.

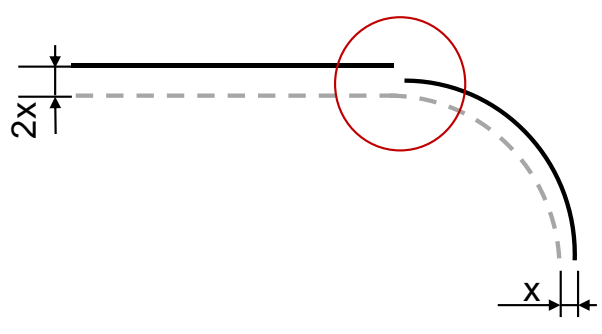

(a) Strain in cylinder is twice of that in dome.

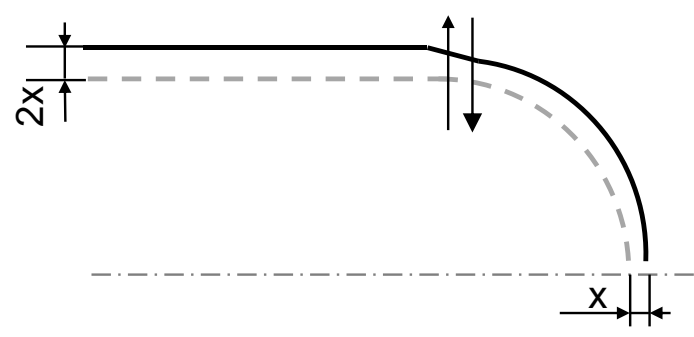

(b) Secondary stresses.

Figure 5. Strains and the resulting secondary stresses in a cylindrical pressure vessel.

In order to design the vessel in such a way that it does not fail at the interface, Equation (9) has to be continuous. This requires that the stresses and in-turn the radii of curvature, pressure, and thickness must be continuous. At the interface of the cylinder and the dome, there is a discontinuity in the radius of curvature, which results in the aforementioned secondary stresses.

In addition, in a wound composite pressure vessel, in order to take advantage of the composite, various ply length and winding angle are used: hoop, helical, and polar winding. Hoop winding occurs in the cylindrical region. The winding angle for this pattern is $90^{\circ}$, which aligns the fibres in the laminate with the direction of the hoop stresses, thus providing maximum strength. Polar winding uses a very low winding angle to cover a vessel from pole to pole in fibre. Lastly, helical winding covers the entire pressure vessel with a layer of uniform thickness having a predetermined winding angle greater than that of polar winding 
but less than that of hoop winding. Here, the fibre is fed sideways along a pressure vessel and translates along a pressure vessels length. While polar winding covers the entire vessel, hoop winding is only possible in the cylindrical section. This limitation causes a thickness jump, which results in an out of plane shear stress (one of the secondary stresses).

Additionally, if one were to design a vessel using netting theory, there would be no way to account for this secondary stress, considering that this approach neglects all out-ofplane bending moments and inter-laminar shear stresses [2,22]. These shear stresses, which will be discussed in the results section, occur mainly near the dome-cylinder interface and result in peak stresses in the vicinity of the junction.

\section{Finite Element Model}

For the analysis, there were three different models which were considered: (i) only a liner; (ii) liner with one wound layer; (iii) complete CPV model as an example; all the models are axisymmetric, liner modelled using CAX4 and wound composite layer using CAX4R elements. All the models were analysed for mesh convergence. The dome contours in (i) and (ii) were varied as explained in the Section 2. Along with this, an additional case, namely, circular domes (termed as Circle), which is common among the liners available on the market, is considered for the analysis. Due to the complex interaction of the boss and the liner, in both cases, the boss was not considered for analysis and this would be the focus of another detailed investigation. Pressure vessels are designed to obtain the highest storage volume in the given space. Due to this, the maximum length and the diameter of the vessel were kept constant for all dome variation. This implies that the length of the cylindrical region varied according to the case. Since the focus of this study is solely on effect of different geometries and not to determine the optimal composite laminate sequence or safe design pressure, a low pressure of $0.1 \mathrm{MPa}(1 \mathrm{bar})$ was applied in all the cases. This provides a simple comparison of each case and is expected to reduce other undesired effects at higher pressure (e.g., numerical stability), which may mask the actual behaviour.

The boundary conditions for all the models are as shown in Figure 6. As a result of the internal pressure, an additional load is acting on the boss system. In order to reduce the number of influencing factors, this is not considered for any of the case. The FEA solver ABAQUS ${ }^{\circledR}$ was used for the analysis. The modelling of the composite overlap was aided by the wound composite modeller tool.

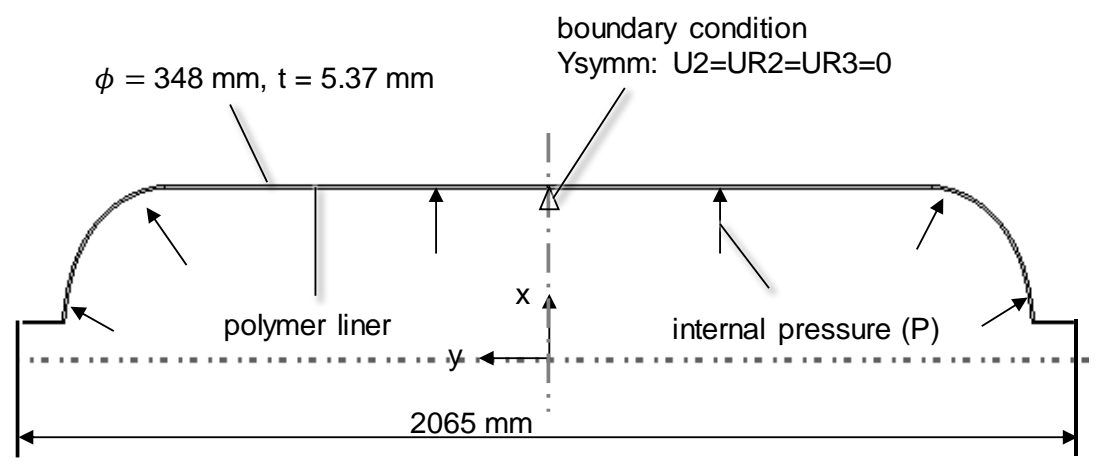

Figure 6. Boundary and loading conditions for the finite element model.

Carbon-Epoxy system was used for the wound layers and a low density polymer liner (the liner material values are as per [23]). The material properties of these materials are provided in the table. For the experimental result and the complete analysis of the CPV, a high density polyethylene liner was used, and its material properties are also provided in the Table 1. However, in Type IV CPV's, the polymer liner is seen to have a negligible load sharing ability compared to the composite [15]. A hard contact boundary condition was used between liner and composite overwrap. 
Table 1. Material parameters

\begin{tabular}{|c|c|c|c|c|c|}
\hline \multicolumn{6}{|c|}{ Carbon-Epoxy UD-Orthotropic } \\
\hline $\begin{array}{c}{[\mathrm{MPa}]} \\
E_{\|}=125588\end{array}$ & $\begin{array}{c}{[\mathrm{MPa}]} \\
E_{1}=7700\end{array}$ & $\begin{array}{c}{[-]} \\
v_{1 \|}=0.3\end{array}$ & $\begin{array}{l}{[-]} \\
v_{1}=0.21\end{array}$ & $\begin{array}{c}{[\mathrm{MPa}]} \\
G_{1}=5600\end{array}$ & $\begin{array}{c}{[\mathrm{MPa}]} \\
G_{1}=3700\end{array}$ \\
\hline \multicolumn{6}{|c|}{ Carbon Epoxy UD-Orthotropic-Strength } \\
\hline [MPa] & [MPa] & [MPa] & {$[\mathrm{MPa}]$} & [MPa] & [MPa] \\
\hline$\sigma_{\|}^{+}=1819$ & $\sigma_{\perp}^{+}=72$ & $\sigma_{\|}^{-}=1150$ & $\sigma_{\perp}^{-}=152$ & $\tau_{\perp \|}=90$ & $\tau_{\perp}=70$ \\
\hline \multicolumn{6}{|c|}{ Liner (LDPE)-Isotropic } \\
\hline \multirow{2}{*}{$\begin{array}{c}{[\mathrm{MPa}]} \\
E=171.4\end{array}$} & [-] & & & & \\
\hline & $v=0.42$ & & & & \\
\hline \multicolumn{6}{|c|}{ Liner (HDPE)-Isotropic } \\
\hline [MPa] & {$[-]$} & & & & \\
\hline$E=1500$ & $v=0.42$ & & & & \\
\hline
\end{tabular}

\section{Results}

This section is divided into three main subsections. Firstly, only the liner was modelled, accounting for nonlinear geometry. Secondly, the same liner geometries are wound with composite material. To reduce complex interactions which could occur, only one composite layer is considered for analysis. Lastly, experimental results of a full scale CPV are presented and discussed. Since the experiment was not a part of this study, complete details about the manufacturing and testing are not discussed.

\subsection{Liner Analysis}

In this subsection, only the liner is analysed. Different dome contours were modelled keeping the total length of the vessel the same. Two different cases were analysed; with and without nonlinear geometry (Nlgeom) activated in ABAQUS ${ }^{\circledR}$. With Nlgeom, ABAQUS ${ }^{\circledR}$ includes terms called as load-stiffeners, caused due to the application of load [24]. In addition, the membrane stiffness in response to transverse loading is considered by including geometric nonlinearity.

From Figures 7 and 8, a clear distinction in the stress peaks at the vicinity of the interface can be observed. In the case where Nlgeom is on, stresses in the cylindrical section are higher than with Nlgeom turned off. With Nlgeom turned on in a shell model, in response to transverse loads (secondary loads), the membrane (strictly speaking in this case the liner) loads contribute much of the stiffness of these structure. With Nlgeom turned off, these loads do not contribute to the structural stiffness and local stress peaks are observed. The stress peaks observed at the extremities are due to the stress concentration at the liner-boss connection region, as in this case no boss system was considered. In all the further case, Nlgeom was activated.

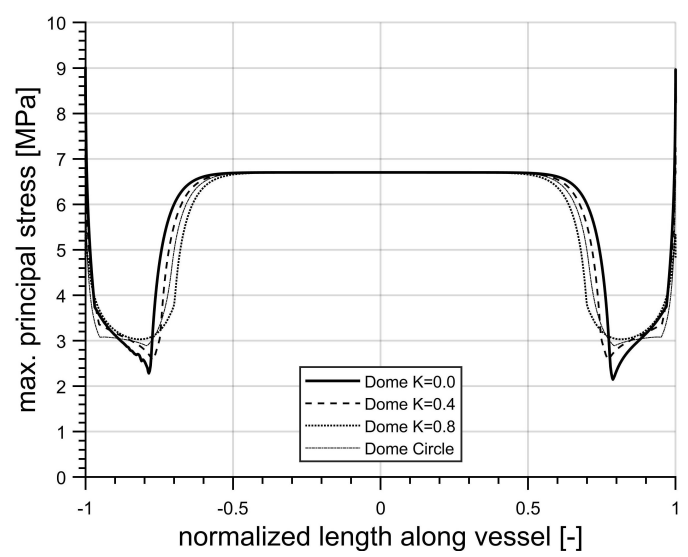

Figure 7. Maximum principal stress in the liner accounting for nonlinear geometry. 


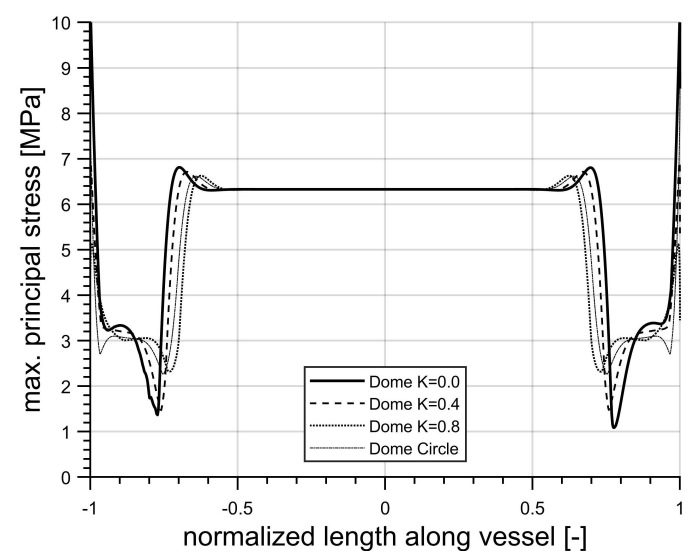

Figure 8. Maximum principle stress in the liner without nonlinear geometry.

\subsection{Composite and Liner Analysis}

Figure 9 shows the maximum principal stress distribution throughout the pressure vessel for different dome contours. The winding angle is calculated using Equation (1), which is only dependent upon the radial coordinate and the cylinder radius and, therefore, constant for all the dome contours. Since the geometry of the cylinder is constant along its length, the stress distribution is seen to be the same for all the cases. Furthermore, the discontinuity of the radius of curvature at the dome-cylinder interface results in stress peaks caused by the addition of local secondary stresses, which was also observed in by Almeida et al. [15].

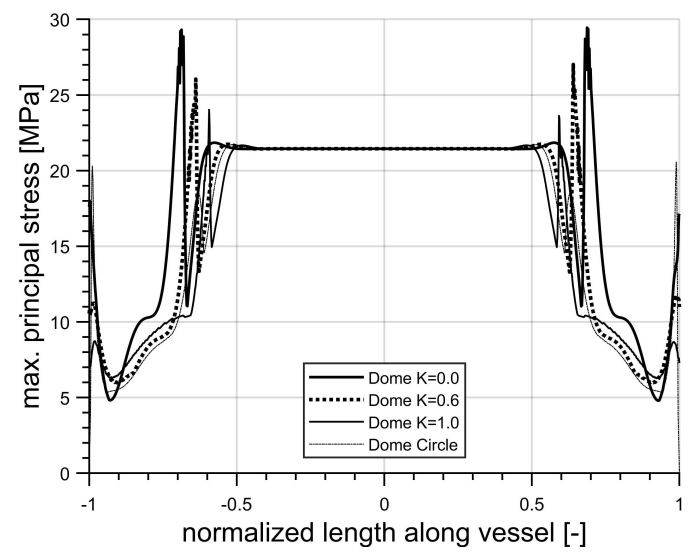

Figure 9. Maximum principal stress in the composite pressure vessel.

In Peters [2], the performance parameter of the pressure vessel is defined as the ratio volumetric energy (pressure $\times$ volume) to the weight of the structure. In order to maximise the performance parameter, the designer can optimise one of the three parameters. Vasiliev et al. [25] have shown that to obtain maximum performance of the vessel, shear stress must be zero. Figure 10 shows the shear strain distribution along the pressure vessel. It is seen that the shear strain is negligible at all the places except at the dome-cylinder and dome-boss interface. In this case, shear strains are very low as the internal pressure is low $(0.1 \mathrm{MPa})$. For a composite pressure vessel, the working pressure will typically reach ca. $70 \mathrm{MPa}$ [1]. In addition, since these pressure vessels are modelled with both hoop and helical winding patterns, there is a difference in thickness that occurs at the interface, which, according to Timoshenko [21], causes a shear stress. As discussed in the Section 3, the discontinuity in the radius of curvature results mostly in bending stresses. These stresses are not exactly at the joint, but in the vicinity of the joint where the secondary stresses reach their maximum. 


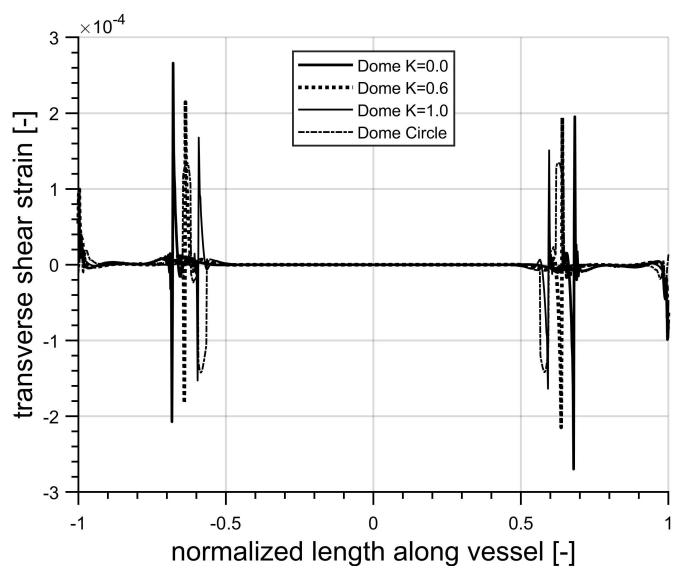

Figure 10. Shearing strain in the composite pressure vessel (CPV).

In fibre reinforced composites, matrix material is mainly responsible to take-up shear loading. As a result of this shear, it can be expected that the stresses in the direction perpendicular to the fibre increases. To analyse this, the local fibre stresses were recorded. The results of the stress ratio is shown in the Figure 11. Similar to the trend seen in Figure 10, the ratio of the stresses $\sigma_{22} / \sigma_{11}$ as $\mathrm{K}$ reduces (for $\mathrm{K}$ values from 0 to 1 ). Furthermore, it is seen that on the dome region, the stresses are a function of the dome contour, as mentioned in [2]. In contrast to designing an optimum vessel (where $K=0.066$, see Equation (5)), the $\mathrm{K}$ can be replaced with $K_{s}=\sigma_{\|}^{+} / \sigma_{\perp}^{+}$which gives a value of 0.039 . From the trend observed in the Figure 11, it can be deduced that for $K_{s}$ the stress ratio in the dome is lower than that for $\mathrm{K}$, meaning higher loading in the fibre direction.

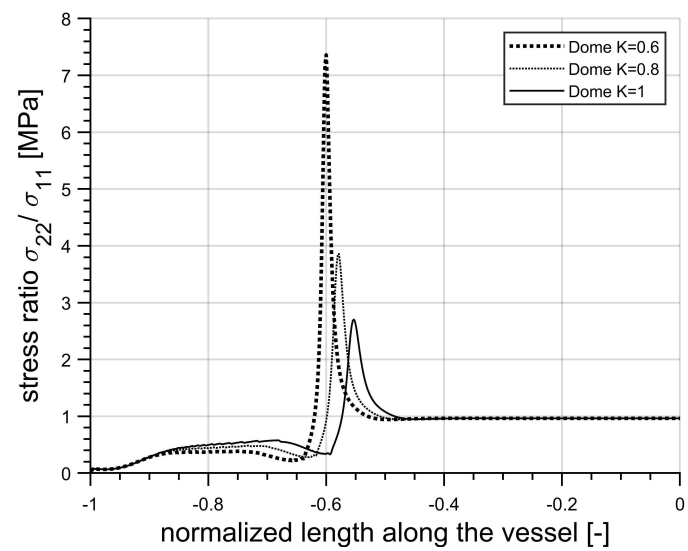

Figure 11. Ratio of fibre stresses, shown only for half length of the CPV.

A hypothesis for the stress peaks seen in the pressure vessel can be deduced by understanding the slopes of the curves in the Figure 3, as shown in the Figure 12. For the cylindrical section, the slope is infinity. For a circular dome contour, the stress peaks are seen to be the minimum at the dome-cylinder interface and for $K=0$ maximum. With some caution it could be said that if the slope is high, the secondary stresses in the junction are low.

In composite pressure vessel having liners, particularly polymer liners, the effect of shear stress is of high importance. Most of the CPV used for hydrogen storage have a polymer liner as a barrier layer and undergo a working pressure of $70 \mathrm{MPa}$. At these high pressures and due the change in the thickness in the laminate layout as mentioned earlier, very high strains can be expected. This phenomena of stress concentration at the dome-cylinder interface was also observed by Lin et al. [16], in the specific experimental case, where high matrix cracking present. According to them one of the causes for this stress concentration and the interlaminar delamination failure at this region is due to the 
geometric discontinuities, which resulted in additional bending moment. This concurs with the results of this article.

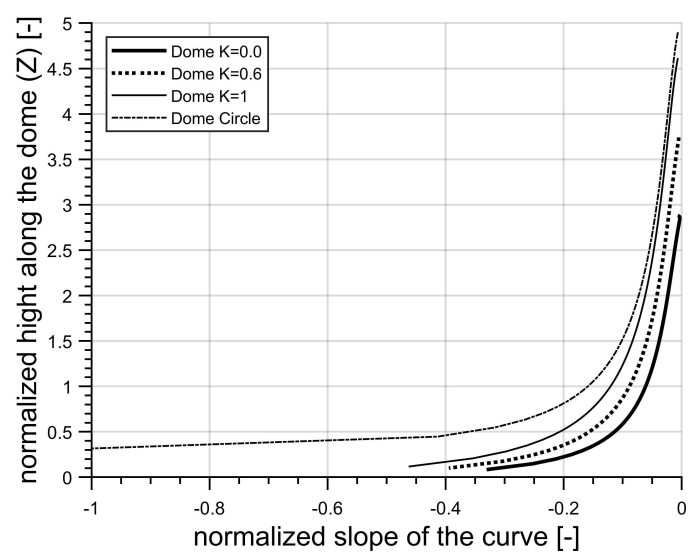

Figure 12. Normalised slopes for varying $\mathrm{K}$ values.

In this article, an experimental case is presented as a comparison. The details of the experiment and the actual experimental pressure curves are out of the purview of this article and are not provided. Figure 13 shows the shear strain distribution in a HDPE liner of a pressure vessel for hydrogen storage which was designed for $150 \mathrm{MPa}$. The dome contour used for the design was calculated from netting theory, which in this case is equivalent to $K=0$. HDPE liner has an extension at failure of ca. $8 \%$.

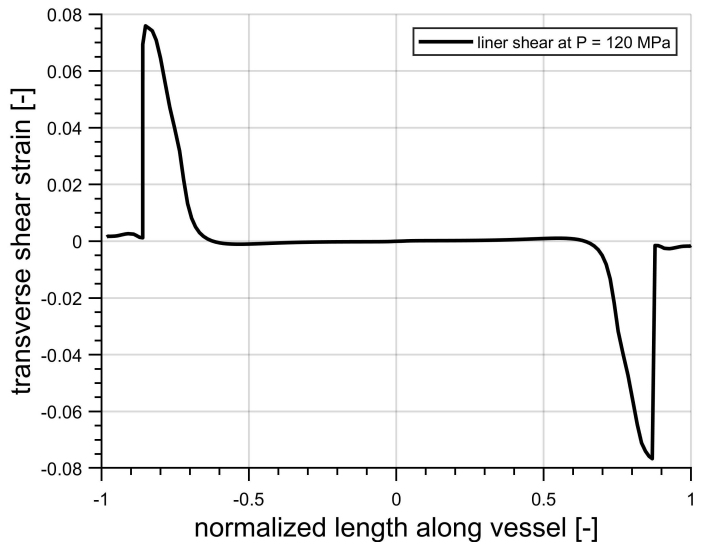

Figure 13. Shear strain in the liner.

Figure 14 shows the shear stress in the helical layer of the composite overwrap. The cross-sectional view of the pressure vessel is provided in the Figure 15. Due to the laminate layout, there is a large change in the thickness at the dome-cylinder interface which is seen. The failure of the vessel occurred at a pressure 113.4 MPa and the failure mechanism is shown in Figure 16. Nevertheless, the effect of the boss, present in this experimental case, is not accounted for and cannot be ruled out. This will be a part of another detailed study. 


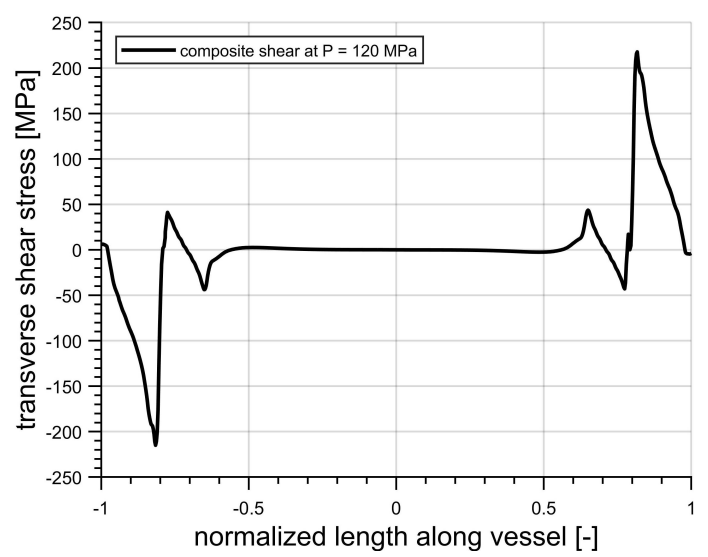

Figure 14. Shear stresses the helical layer of the composite.

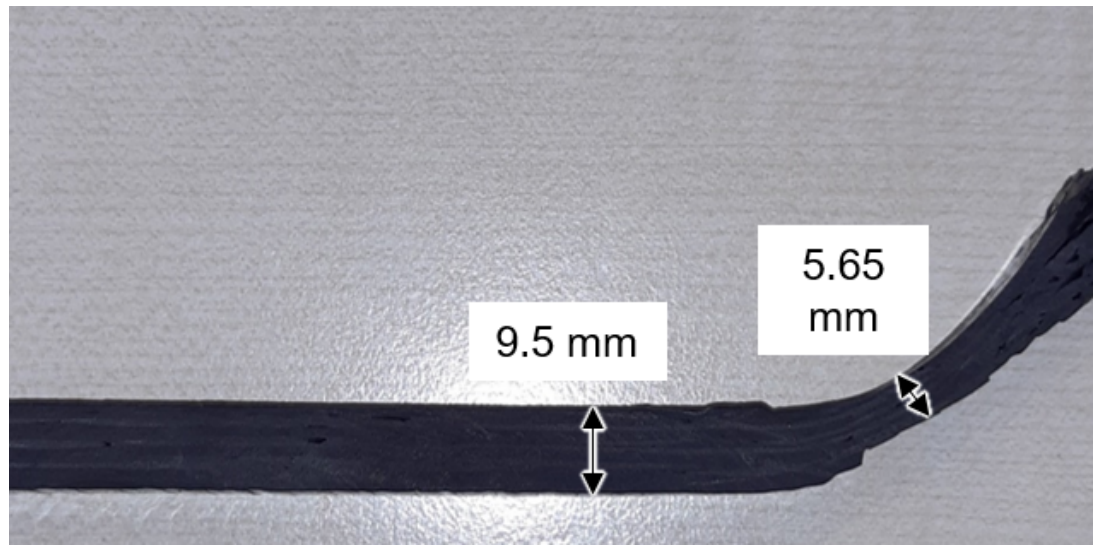

Figure 15. Sectional view of a dome-cylinder interface showing the thickness jump due to the hoop and polar winding.

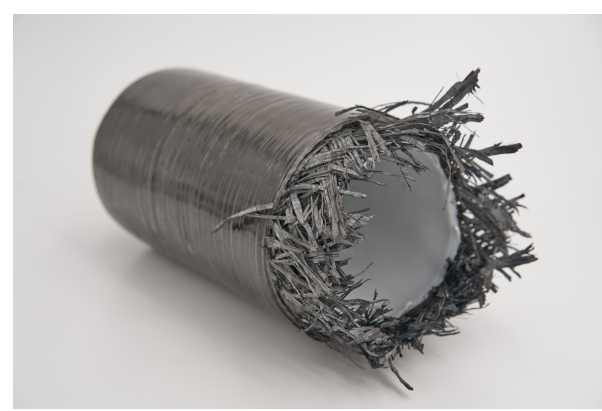

(a) Cylindrical section after failure.

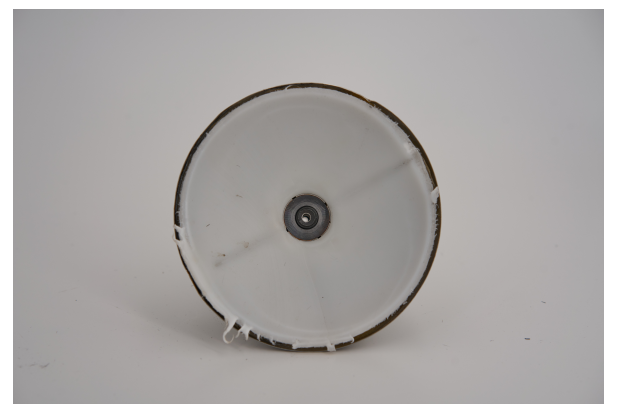

(b) Dome region after failure.

Figure 16. Failure mechanism of the pressure vessel. Failure pressure of 113.4 MPa. One of the reasons for the failure could be the secondary stress at the dome-cylinder interface. The influence of the metallic boss present in this case is not considered; however, it cannot be neglected.

\section{Conclusions}

A numerical analysis of pressure vessel with different dome contours was presented. The focus was to analyse the stress distribution at the dome-cylinder interface and on the dome contour itself. Three different cases were presented. First, only liner was modelled and analysed for the influence of the nonlinear geometry option in ABAQUS ${ }^{\circledR}$. Due to the activation of the load-stiffeners, the stress in the cylindrical section was higher and the stress peaks at the dome-cylinder interface were not observed when compared to the analysis without activation of nonlinear geometry. Secondly, the same liner model was overwrapped with one layer of carbon-epoxy composite with the same winding angle for all the cases. There was negligible secondary stress observed in the dome section, which is 
in agreement with the analytical results. Considerable secondary stresses are observed at the dome-cylinder interface in all the cases. There was an increasing trend in the secondary stress with a reduction of the slope at the vicinity of the interface. This secondary stress is caused due to the bending and out of plane shear stress, the former is due to the change in the radius of curvature and the latter is expected to be caused by a thickness change and observed to reach a maximum at a distance from the dome-cylinder joint and not exactly at the joint itself. Lastly, the shear stress distribution in a real pressure vessel with its dome designed using netting theory and its failure mechanism is presented. To this end, the important understanding is that the secondary stress has an impact mainly at the dome-cylinder interface, especially critical for thick walled cylindrical composite pressure vessels which are manufactured for high pressure storage and crucial to be considered during the design phase. While this could also be present at the boss-dome junction, this requires a much more complex analysis. These numerical results require more complex experimental validation with suitable strain measurement techniques.

Author Contributions: Formal analysis, K.C.J. and M.W.; Funding acquisition, J.S.; Investigation, K.C.J.; Project administration, J.S.; Resources, T.G.; Supervision, T.G.; Writing—original draft, K.C.J. and M.W.; Writing-review and editing, T.G. and J.S. All authors have read and agreed to the published version of the manuscript.

Funding: This research received no external funding.

Acknowledgments: The first author acknowledges support from Dassault Systèmes for the composite modelling in ABAQUS ${ }^{\circledR}$. J. Sackmann acknowledges the How2MultiWind research project funding from the Federal Ministry for Economic Affairs and Energy (BMWi).

Conflicts of Interest: The authors declare no conflict of interest.

\section{References}

1. Stolten, D.; Emonts, B.; Grube, T. (Eds.) Der 4. Deutsche Wasserstoff-Congress 2008-Tagungsband. In Schriften des Forschungszentrums Jülich Reihe Energie \& Umwelt; Forschungszentrum Zentralbibliothek: Jülich, Germany, 2008.

2. Peters, S.T. (Ed.) Composite Filament Winding; ASM International: Materials Park, OH, USA, 2011.

3. Lengersdorf, M. Produktorientiertes Geflecht-Preforming für Druckbehälter in Faserverbundbauweise. Ph.D. Thesis, RWTH Aachen, Aachen, Germany, 2017.

4. Askeland, D.R. The Science and Engineering of Materials; Springer: Dordrecht, The Netherlands, 1991.

5. Tew, B.W. Preliminary Design of Tubular Composite Structures Using Netting Theory and Composite Degradation Factors. J. Press. Vessel Technol. 1995, 117, 390-394. [CrossRef]

6. Gheshlaghi, R.M.; Hojjati, M.H.; Daniali, H.R.M. Analysis of Composite Pressure Vessels. In Fracture of Nano and Engineering Materials and Structures; Gdoutos, E.E., Ed.; Springer: Dordrecht, The Netherlands, 2006; Volume 117, pp. $335-336$.

7. Zhang, Q.; Xu, H.; Jia, X.; Zu, L.; Cheng, S.; Wang, H. Design of a $70 \mathrm{MPa}$ type IV hydrogen storage vessel using accurate modeling techniques for dome thickness prediction. Compos. Struct. 2020, 236, 111915. [CrossRef]

8. Mallick, K.; Cronin, J.; Arzberger, S.; Tupper, M.; Grimes-Ledesma, L.; Lewis, J.; Paul, C.; Welsh, J. Ultralight Linerless Composite Tanks for In-Space Applications. In Space 2004 Conference and Exhibit; American Institute of Aeronautics and Astronautics, Ed.; American Institute of Aeronautics and Astronautics: Reston, VA, USA, 2004; p. 121.

9. Gray, D.; Moser, D. Finite Element Analysis of a Composite Overwrapped Pressure Vessel. In 40th AIAA/ASME/SAE/ASEE Joint Propulsion Conference and Exhibit; American Institute of Aeronautics and Astronautics: Reston, VA, USA, 2004 ; p. 3506.

10. Multhoff, J.B.; Krieger, J. Effective structural design procedure for composite hydrogen tanks. In Proceedings of the 18th World Hydrogen Energy Conference 2010-WHEC 2010, Forschungszentrums Jülich, Jülich, 16-21 May 2010; Volume 78-4, ISBN 978-3-89336-654-5.

11. Magneville, B.; Gentilleau, B.; Villalonga, S.; Nony, F.; Galiano, H. Modeling, parameters identification and experimental validation of composite materials behavior law used in 700 bar type IV hydrogen high pressure storage vessel. Int. J. Hydrog. Energy 2015, 40, 13193-13205. [CrossRef]

12. Willardson, R.P.; Gray, D.L.; DeLay, T.K. Improvements in FEA of Composite Overwrapped Pressure Vessels. In Proceedings of the Society for the Advancement of Material and Porcess Engineering-Fall Technical Conference, 24 April 2009 Wichita, KS, USA, 2009.

13. Tam, W.H.; Griffin, P.S.; Jackson, A.C. Design and manufacture of a composite overwrapped pressurant tank assembly. In Proceedings of the 38th AIAA/ASME/SAE/ASEE Joint Propulsion Conference \& Exhibit, Indianapolis, Indiana, 7-10 July 2002.

14. Park, Y.H.; Sakai, J. Optimum design of composite pressure vessel structure based on 3-dimensional failure criteria. Int. J. Mater. Form. 2020, 13, 957-965. [CrossRef] 
15. Almeida, J.H.S.; Faria, H.; Marques, A.T.; Amico, S.C. Load sharing ability of the liner in type III composite pressure vessels under internal pressure. J. Reinf. Plast. Compos. 2014, 33, 2274-2286. [CrossRef]

16. Lin, S.; Yang, L.; Xu, H.; Jia, X.; Yang, X.; Zu, L. Progressive damage analysis for multiscale modelling of composite pressure vessels based on Puck failure criterion. Compos. Struct. 2021, 255, 113046. [CrossRef]

17. Koussios, S. Filament Winding: A Unified Approach; DUP Science: Delft, The Netherlands, 2004.

18. Zu, L.; Xu, H.; Wang, H.; Zhang, B.; Zi, B. Design and analysis of filament-wound composite pressure vessels based on non-geodesic winding. Compos. Struct. 2019, 207, 41-52. [CrossRef]

19. Koussios, S.; Bergsma, O.K. Friction Experiments for Filament Winding Applications. J. Thermoplast. Compos. Mater. 2006, 19, 5-34. [CrossRef]

20. Hartog, J.P.D. Advanced Strength of Materials; Dover Civil and Mechanical Engineering, Dover Publications: Newburyport, MA, USA, 2014.

21. Timoshenko, S. Strength of Materials, 3rd ed.;CBS Publishers \& Distributors: New Delhi, India, 2002.

22. Moser, K. Faser-Kunststoff-Verbund: Entwurfs- und Berechnungsgrundlagen; VDI-Buch, Springer: Berlin/Heidelberg, Germany, 1992. [CrossRef]

23. Barboza Neto, E.S.; Chludzinski, M.; Roese, P.B.; Fonseca, J.; Amico, S.C.; Ferreira, C.A. Experimental and numerical analysis of a LLDPE/HDPE liner for a composite pressure vessel. Polym. Test. 2011, 30, 693-700. [CrossRef]

24. Dassault Systèmes Simulia Corp. Abaqus 6.14 Documentation; Dassault Systèmes Simulia Corp: Johnston, RI, USA, 2014.

25. Vasiliev, V.V.; Krikanov, A.A.; Razin, A.F. New generation of filament-wound composite pressure vessels for commercial applications. Compos. Struct. 2003, 62, 449-459. [CrossRef] 